\title{
PROPOSAL FOR STANDARDIZATION OF RADIOGRAPHIC STUDIES ON THE HIP AND PELVIS
}

Giancarlo Cavalli Polesello', Tarsila Sato Nakao ${ }^{2}$, Marcelo Cavalheiro de Queiroz ${ }^{3}$, Daniel Daniachi ${ }^{3}$, Walter Ricioli Junior ${ }^{3}$, Rodrigo Pereira Guimarães ${ }^{4}$, Emerson Kiyoshi Honda ${ }^{5}$, Nelson keiske Ono ${ }^{6}$

\section{ABSTRACT}

Diagnoses of hip and pelvis disorders are based on the detailed medical history, physical examination and laboratory tests, as appropriate for each condition. Plain radiography is still the initial examination of choice and, because of its importance, there is a need to standardize radiographic studies, both in relation to execution and in radiographic series, according to the different pathological conditions. The aim of this paper was to propose standardization for the main radiographic views of the hip and pelvis, and with regard to performing specific series for different pathological conditions, and to provide technical guidance for achieving these aims.

Keywords - Hip/pathogy; Hip/radiography; Pelvis/pathogy; Pelvis/radiography

\section{INTRODUCTION}

The diagnosis of hip and pelvic disorders is based on detailed clinical history, physical examination and laboratory tests, as appropriate for each condition.

Plain radiography is still the initial examination of choice, although computed tomography and nuclear magnetic resonance are useful for diagnostic confirmation ${ }^{(1,2)}$.

In view of the importance of radiography, there is a need to standardized radiographic studies, both in relation to execution and in radiographic series, according to the different pathological conditions. The aim of this article is to propose standardization for the main radiographic views of the hip and pelvis, and with regard to performing specific series for different pathological conditions, providing technical guidance for achieving these aims.

\section{RADIOGRAPHIC VIEWS}

\section{A) Non-traumatic series}

1) Anteroposterior (AP) pelvic radiograph:
- Patient in supine or orthostatic position;

- Beam incident on median line just above the pubic symphysis, feet rotated internally from 15 to $20^{\circ}$ (for correction of the neck anteversion angle), so that the greater trochanter does not overlap the femoral neck (Figure 1);

- It should be possible to visualize the coccyx aligned with the pubic symphysis, $2.5 \mathrm{~cm}$ cranial in the female sex and $1.5 \mathrm{~cm}$ in the male sex. The obturator foramens should be symmetrical ${ }^{(3)}$ (Figure 2);

- The iliopectineal line, ilioischial or Köehler's line ${ }^{(4)}$, teardrop (lower limit of the acetabulum), acetabular roof and edges of the anterior and posterior walls can be observed (Figure 3); and

- The AP pelvic radiograph is the main view in the radiographic series of the hip and of the pelvis; however, their performance with stress is controversial in literature. Conrozier et $a l^{(5)}$ and Vanni et $a l^{(6)}$ demonstrated that there is only a decrease of the articular space in patients with coxarthrosis, in a

\footnotetext{
1 - Assistant Professor with Doctoral Degree; Assistant of the Hip Group of the School of Medical Sciences, Santa Casa de São Paulo - São Paulo, SP, Brazil.

2 - Orthopedist; Former Intern of the Hip Group of the School of Medical Sciences, Santa Casa de São Paulo - São Paulo, SP, Brazil.

3 - Orthopedist; Assistant of the Hip Group of the School of Medical Sciences, Santa Casa de São Paulo - São Paulo, SP, Brazil.

4 - Teaching Instructor with Master's Degree; Assistant of the Hip Group of the School of Medical Sciences, Santa Casa de São Paulo - São Paulo, SP, Brazil.

5 - Teaching Instructor with Doctoral Degree; Senior Member of the Hip Group of the School of Medical Sciences, Santa Casa de São Paulo - São Paulo, SP, Brazil.

6 - Assistant Professor with Doctoral Degree; Head of the Hip Group of the School of Medical Sciences, Santa Casa de São Paulo - São Paulo, SP, Brazil.

Study conducted at the Department of Orthopedics and Traumatology of the School of Medical Sciences, Santa Casa de São Paulo - Director: Prof. Dr. Osmar Avanzi. Mailing address: Rua Dr. Cesário Motta Júnior, 112, Prédio Ortopedia, 2º andar, Sala Quadril - 01221-020 - São Paulo, SP, Brazil. Email: dot.quadril@hotmail.com Study received for publication: 1/11/2011, accepted for publication: 3/25/2011.
}

The authors declare that there was no conflict of interest in conducting this work 


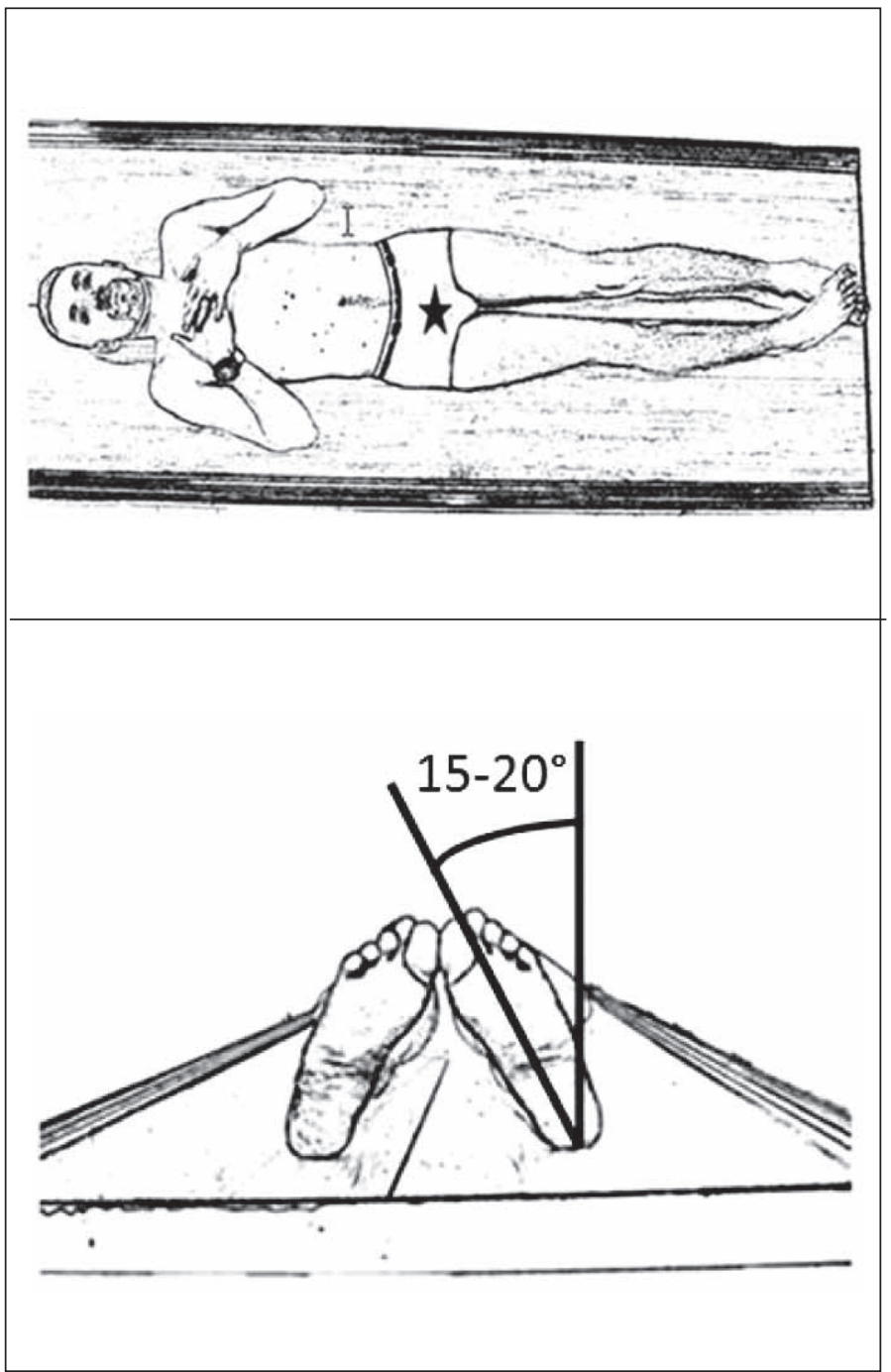

Figure 1 - Anteroposterior pelvic radiograph: positioning of patient supine with the lower limbs rotated internally from 15 to 20 degrees; beam incident on the median line, just above the pubic symphysis.

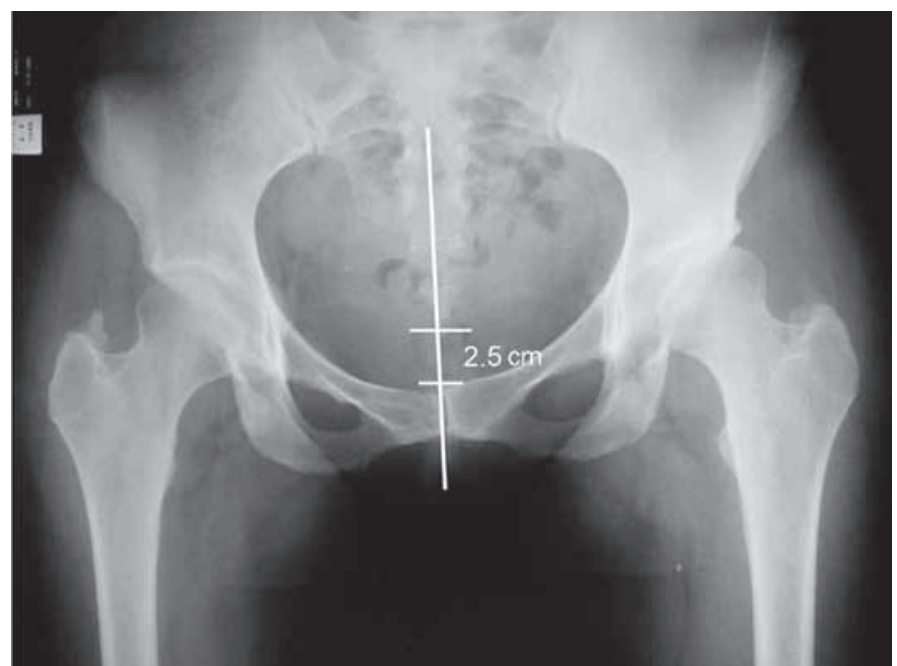

Figure 2 - Anteroposterior pelvic radiograph executed with correct technique. Observe the alignment of the coccyx with the pubic symphysis. The coccyx should be located cranially, no further than $2.5 \mathrm{~cm}$ from the pubic symphysis.

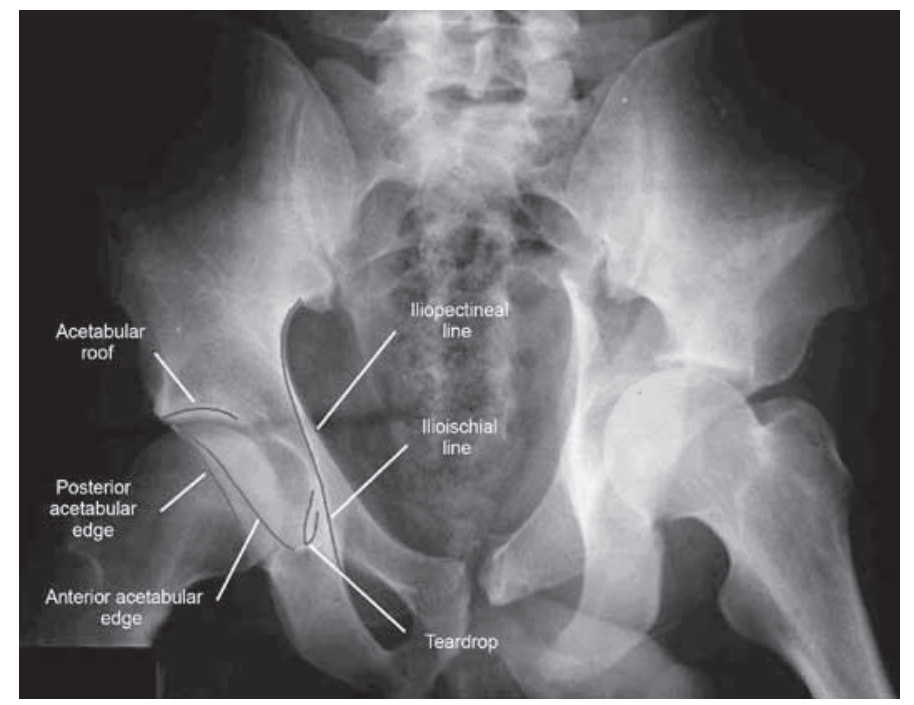

Figure 3 - Anteroposterior pelvic radiograph and the main structures identified.

comparison with unstressed radiography. However, in patients with normal hips or in cases of initial arthrosis, the use of stressed radiography is not necessary ${ }^{(6-8)}$.

2) Lequesne's false profile ${ }^{(9)}$ :

- It is a false profile, as it corresponds to the profile of the head and of the proximal femur, and not of the acetabulum (Figure 4);

- Patient in orthostatic position, with the back tilted $65^{\circ}$ anteriorly in relation to the film chassis, both lower limbs in external rotation, with the affected limb (limb furthest from the chassis) perpendicular to the chassis and the contralateral limb parallel to the chassis (Figure 5);

- When properly executed, observe between the femoral heads the distance corresponding to the diameter of a femoral head (Figure 6); and

- It is a useful view for the visibility of the medial and anterosuperior impingement of the coxofemoral joint. Therefore, it is important for the evaluation of coxarthrosis and acetabular dysplasia ${ }^{(2,10,11)}$.

3) Ducroquet's profile:

- Patient positioned supine, affected hip with flexion of $90^{\circ}$ and abduction of $45^{\circ}$ (this radiograph therefore requires good hip mobility) (Figure 7);

- Beam centered vertically on the coxofemoral joint; - We can observe the profile of the femoral neck, with good visibility of the anterosuperior region of the femoral head-neck transition, the most frequent site of CAME type femoroacetabular impingement. Besides the neck, we can visualize the acetabular roof 


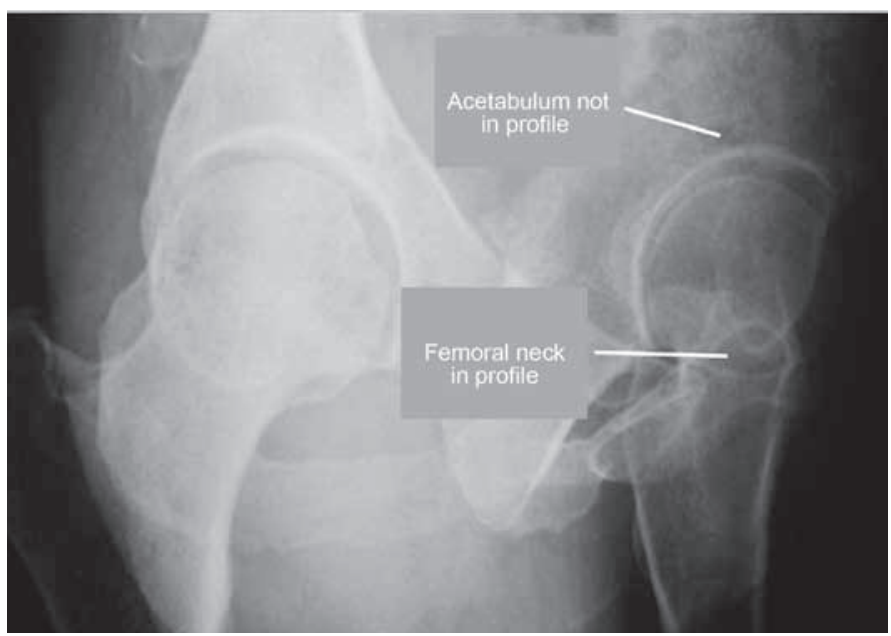

Figure 4 - Lequesne's false profile radiograph, called falseprofile as it corresponds to the profile of the head and of the proximal femur, and not of the acetabulum.
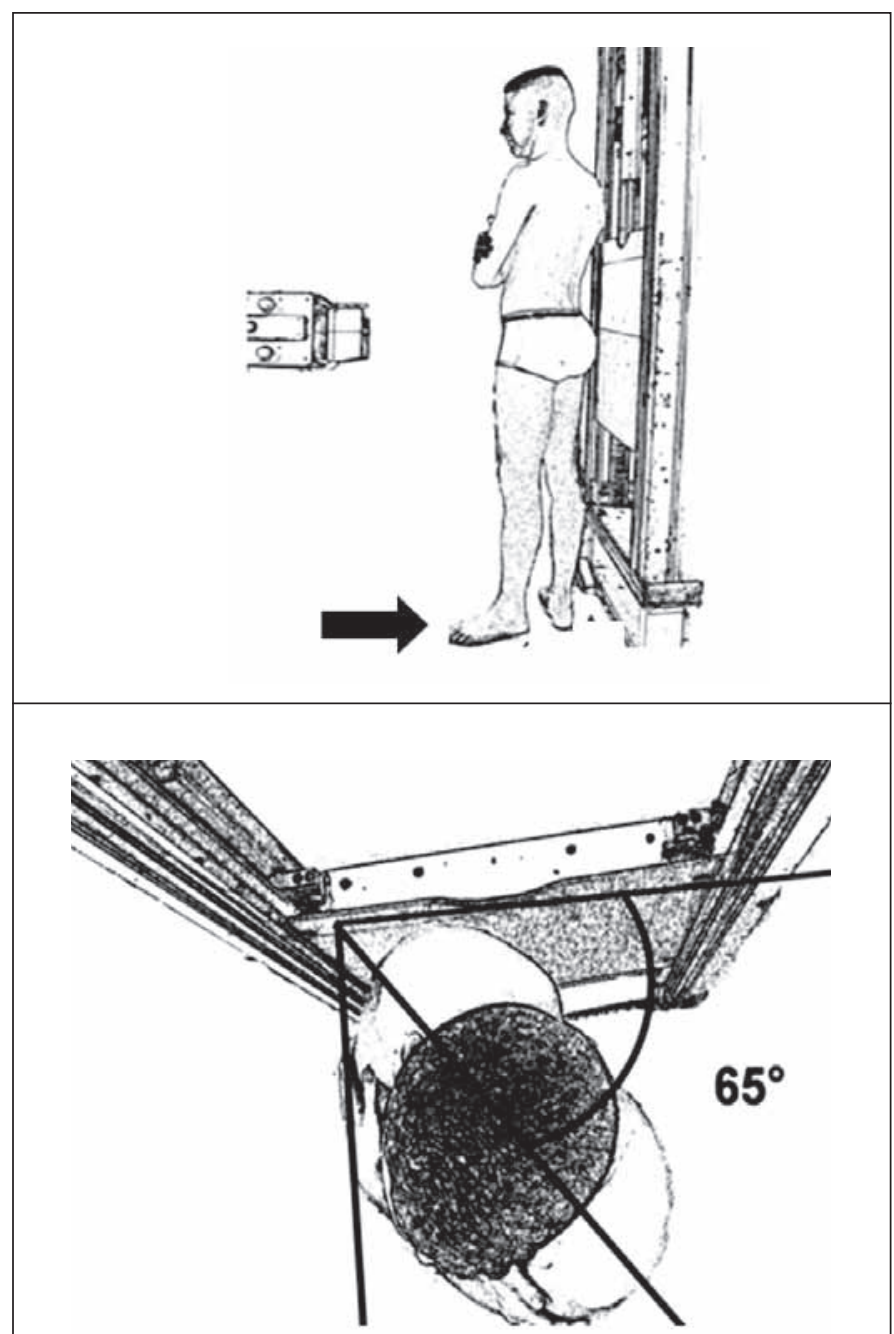

Figure 5 - Lequesne's false profile radiograph. Observe patient's positioning with the affected left lower limb further from the chassis. Patient in orthostatic position, with the back tilted $65^{\circ}$ anteriorly in relation to the film chassis, both lower limbs in external rotation, with the affected limb perpendicular to the chassis and the contralateral limb parallel to the chassis.

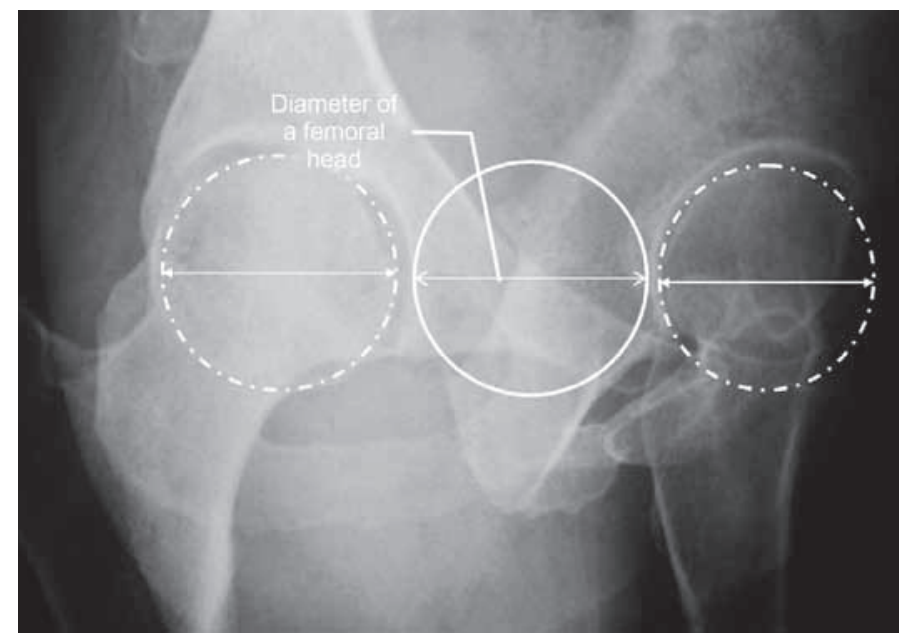

Figure 6 - Lequesne's false profile radiograph executed with correct technique. Observe the distance between the two heads corresponding to the diameter of one of them.

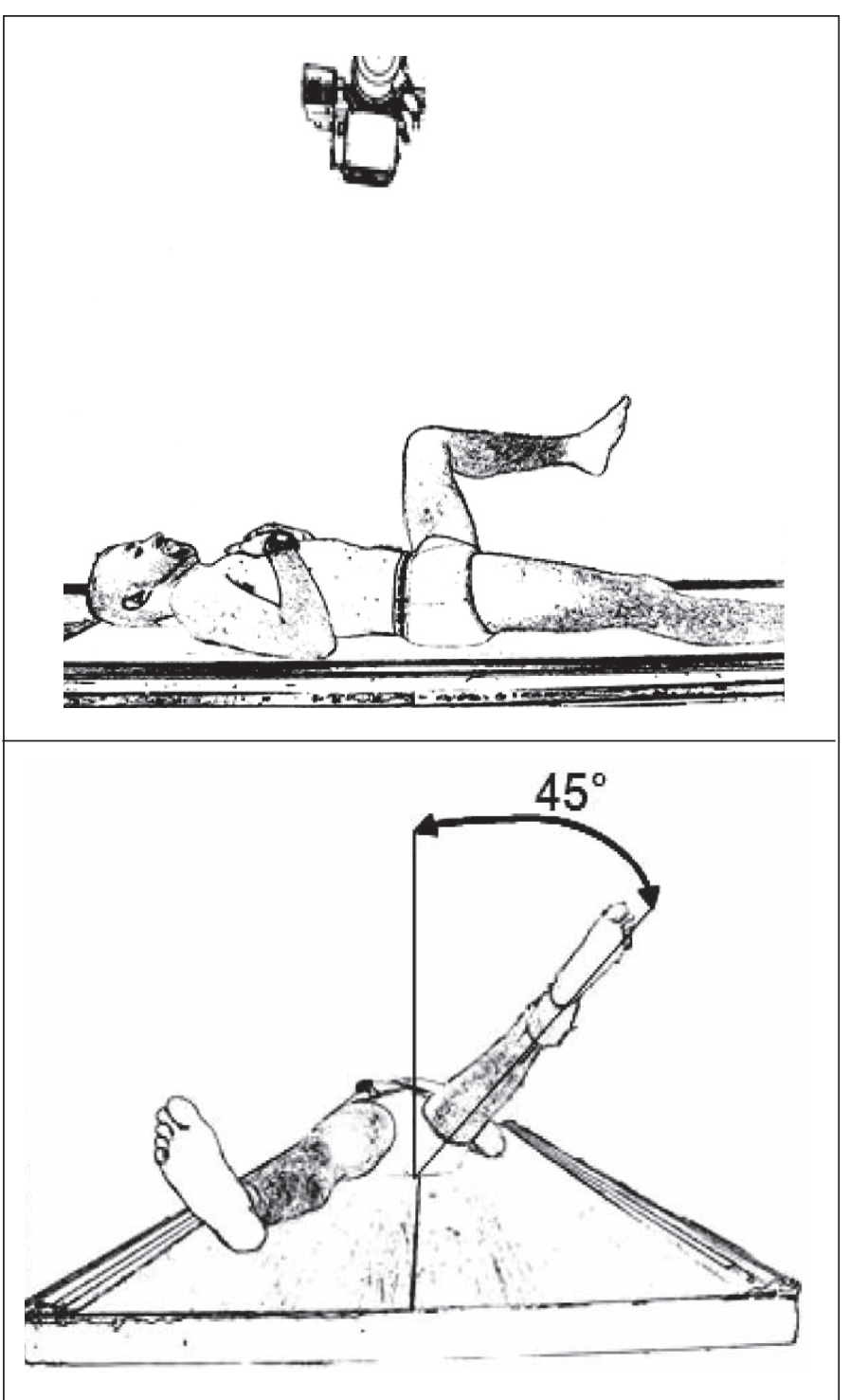

Figure 7 - Ducroquet profile view. Patient in supine position, affected hip with flexion of $90^{\circ}$ and abduction of $45^{\circ}$. Beam centered vertically on the coxofemoral joint. 
and identify the presence of an intra-articular foreign body (Figure 8);

- The Dunn view is a similar profile, performed with hip flexion of $45^{\circ}$ and abduction of $20^{\circ}$. In this view we can also clearly observe the anterosuperior segment of the femoral head-neck transition; and

- It is also possible to measure the alpha angle in both views (angle formed between the longitudinal axis of the femoral neck and a line passing through the center of rotation of the femoral head and through the point of the head-neck junction from where the distance to the center of the head exceeds the radius, i.e., loses sphericity. Its normal value should not exceed $\left.55^{\circ}\right)^{(3,12,13)}$ (Figure 9).

4) Arcelin's surgical profile or cross table view:

- Patient in supine position with flexion of 90 degrees of the contralateral hip;

- The X-ray tube should be angled $45^{\circ}$ cranially in the horizontal plan, towards the thigh root (does not require mobilization of the affected hip, and is ideal for traumatized patients) (Figure 10); and

- Observe the femoral neck in profile and the headneck transition.

5) Lauenstein pelvic radiograph (frog position):

- Patient in supine position with double abduction of the lower limbs; beam incident on median line, just above the pubic symphysis, oriented vertically (Figure 11).

Given the superimposition of images on the femoral side and on the acetabular side, it is the same as a frontal pelvic radiograph, and its usefulness in adults is questionable.

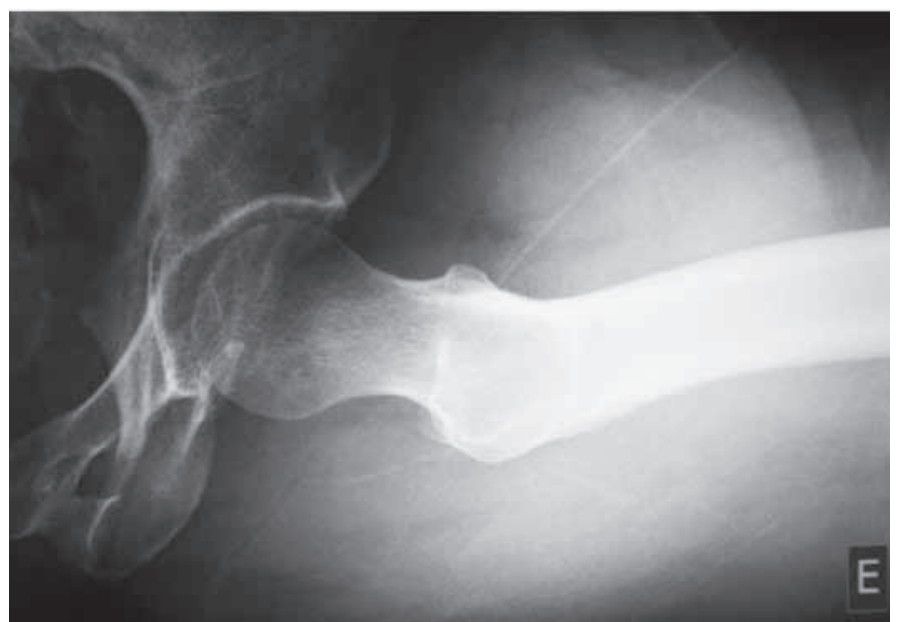

Figure 8 - Radiograph in Ducroquet profile view.

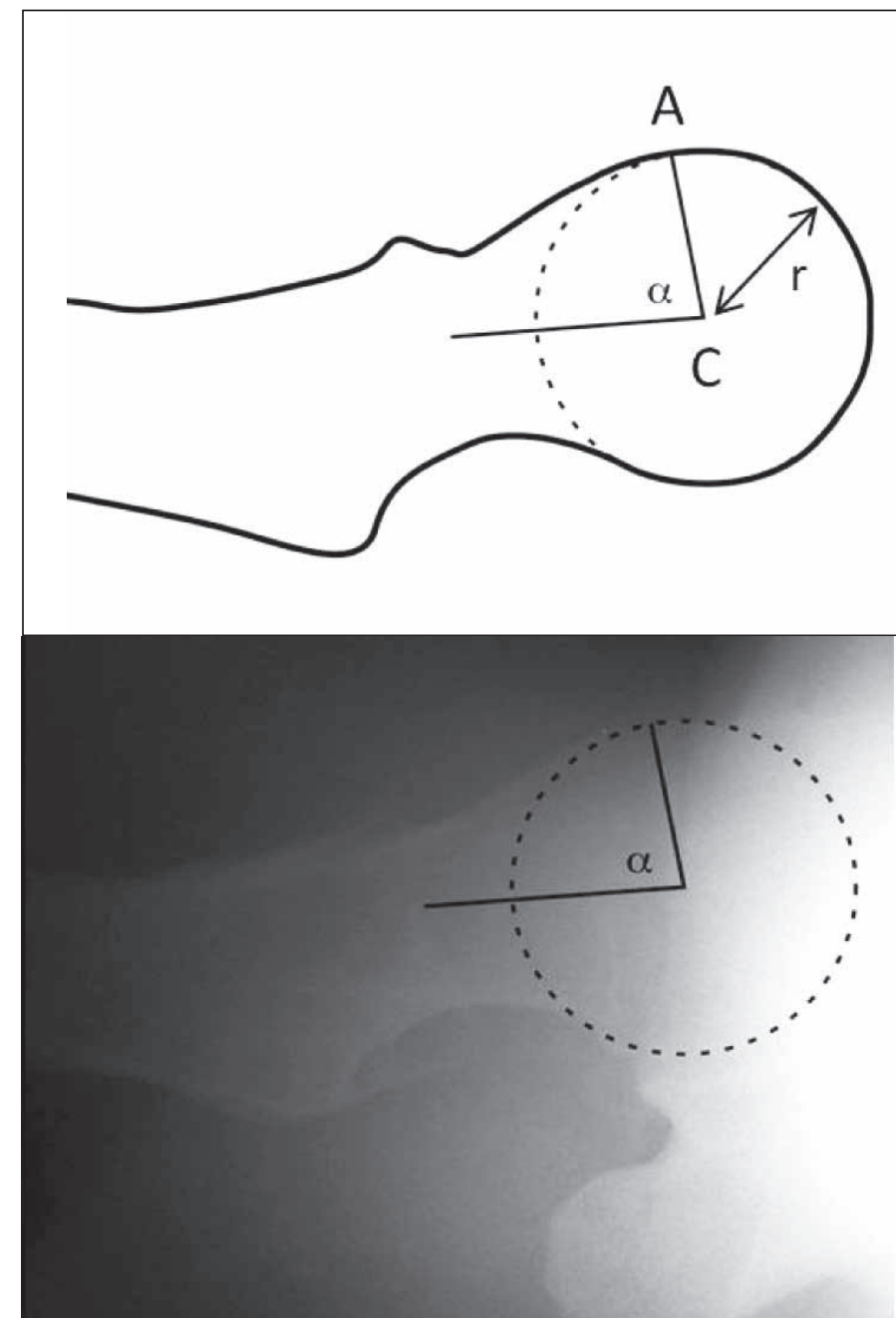

Figure 9 - Measurement of the alpha angle (in the Ducroquet profile view: angle formed by the longitudinal axis of the femoral neck and line AC (A - point of loss of sphericity of the head-neck junction, $\mathrm{C}$ - center of the head, $r$ - radius of the femoral head).

\section{B) Traumatic series}

1) Alar ${ }^{(14)}$ :

- Patient in supine position with rotation of $45^{\circ}$ over the affected side; beam centered vertically on the thigh root (Figure 12);

- It evidences the iliac wing, sacroiliac joint, posterior column and anterior acetabular wall (Figure 13);

- Indicated mainly for physical trauma, especially acetabular fractures ${ }^{(15,16)}$.

2) Protrusive or foraminal view ${ }^{(14)}$ :

- Patient in supine position rotated $45^{\circ}$ over the unaffected side; beam centered vertically on the thigh root (Figure 14);

- It evidences anterior column and posterior acetabular wall (Figure 15); and

- Indicated mainly for physical trauma, especially acetabular fractures ${ }^{(15,16)}$. 


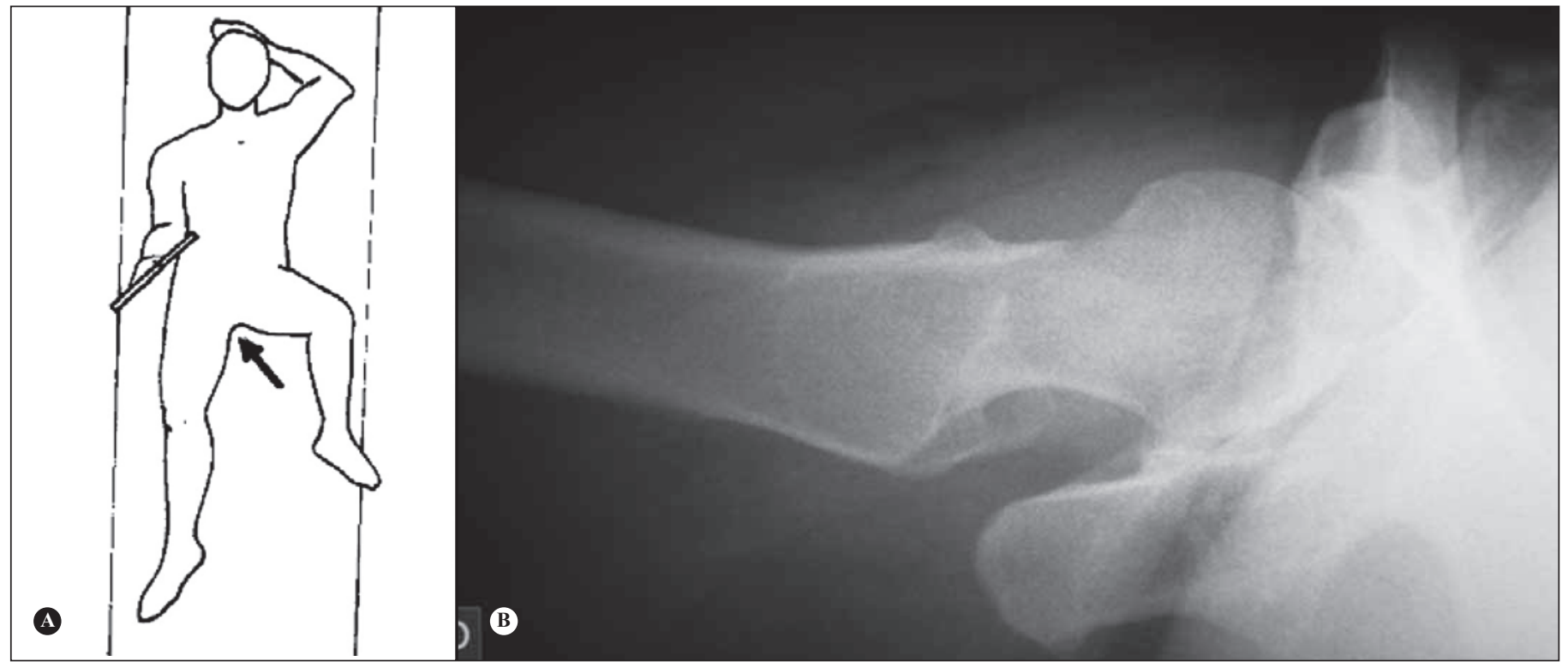

Figure $10-$ A) Surgical profile view. Patient supine, the X-ray tube should be angled $45^{\circ}$ cranially in the horizontal plane, towards the thigh root. B) Radiograph in surgical profile view.

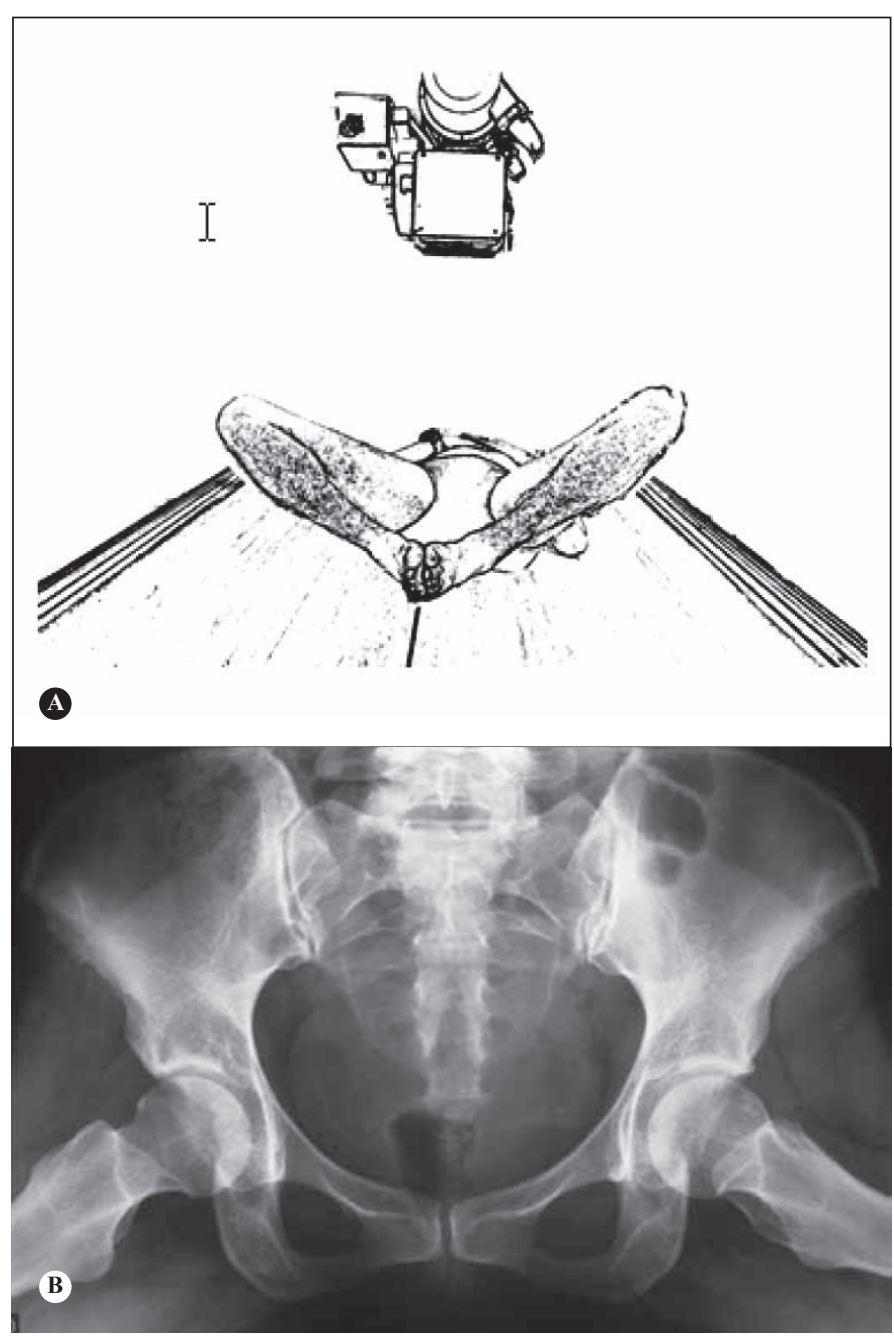

Figure 11 - A) Lauenstein pelvic radiograph. Patient in supine position with double abduction of the lower limbs; beam incident on the median line, just below the pubic symphysis, oriented vertically. B) Lauenstein pelvic radiograph.

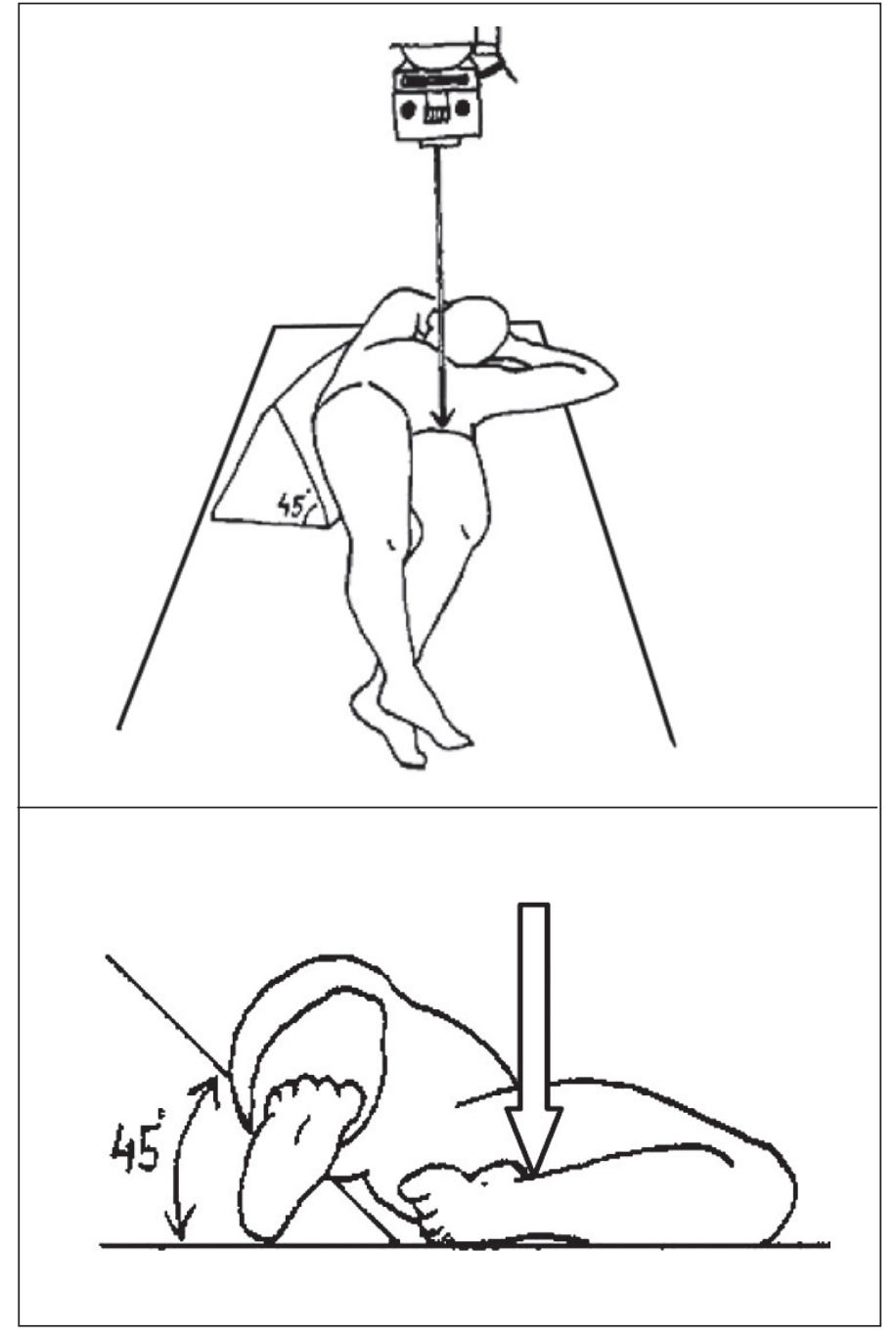

Figure 12 - Alar oblique view of pelvis. Patient in supine position with rotation of $45^{\circ}$ over the affected side; beam centered vertically on the thigh root. 


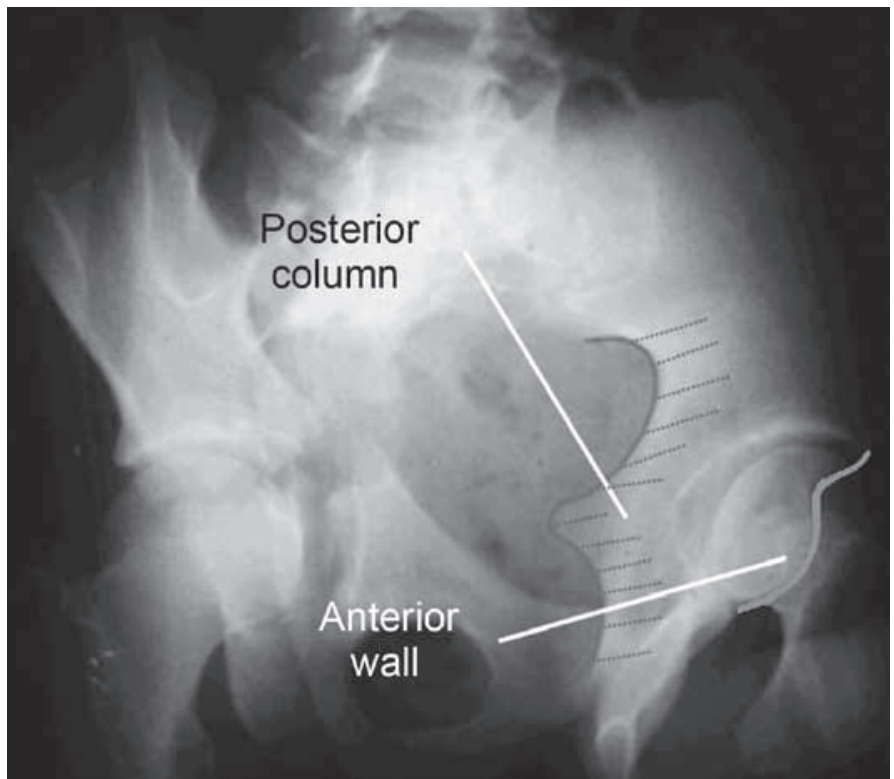

Figure 13 - Alar pelvic radiograph of the left hip.

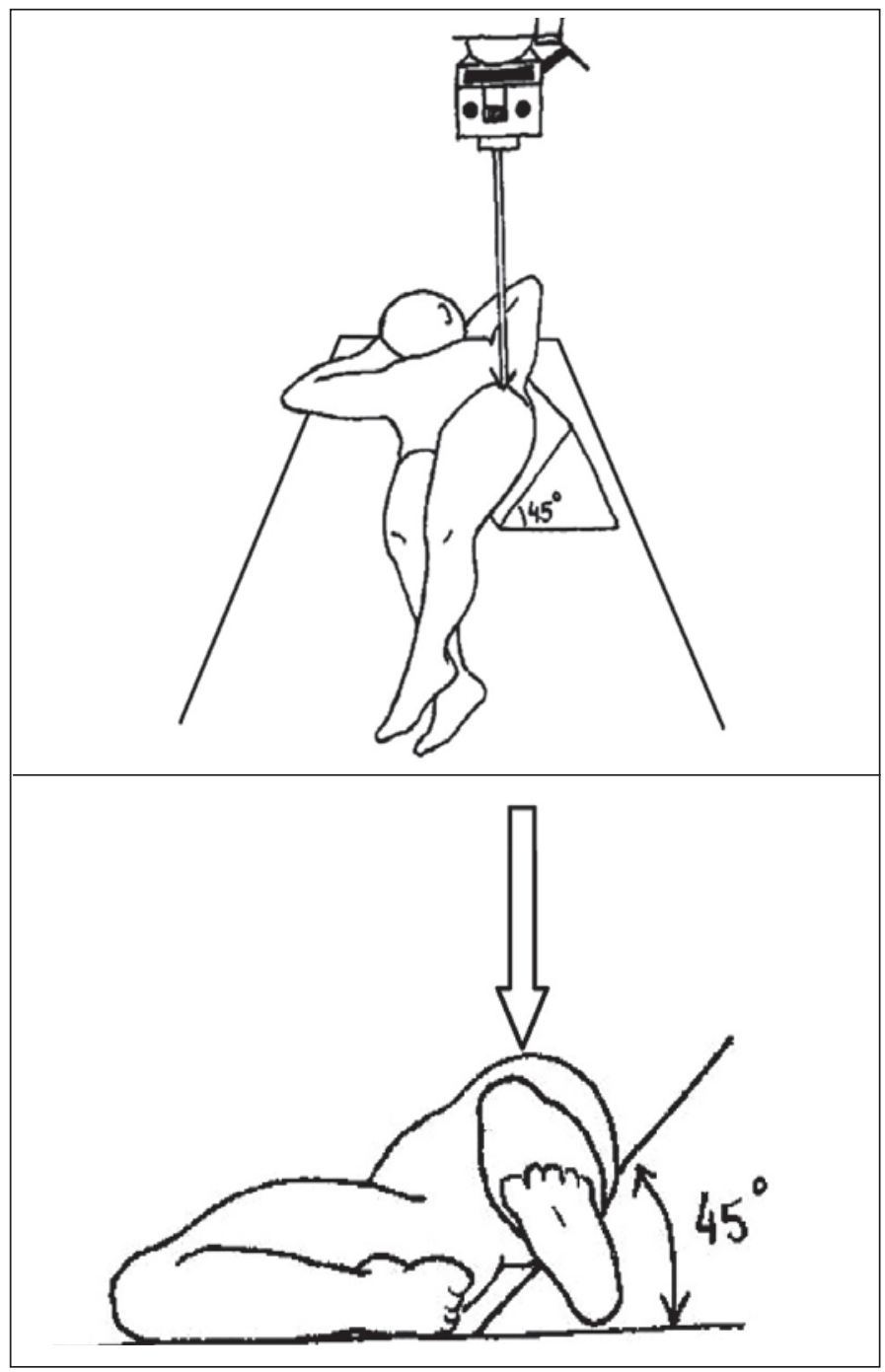

Figure 14 - Foraminal oblique view of the pelvis. Patient in supine position with rotation of $45^{\circ}$ over the unaffected side; beam centered vertically on the thigh root.

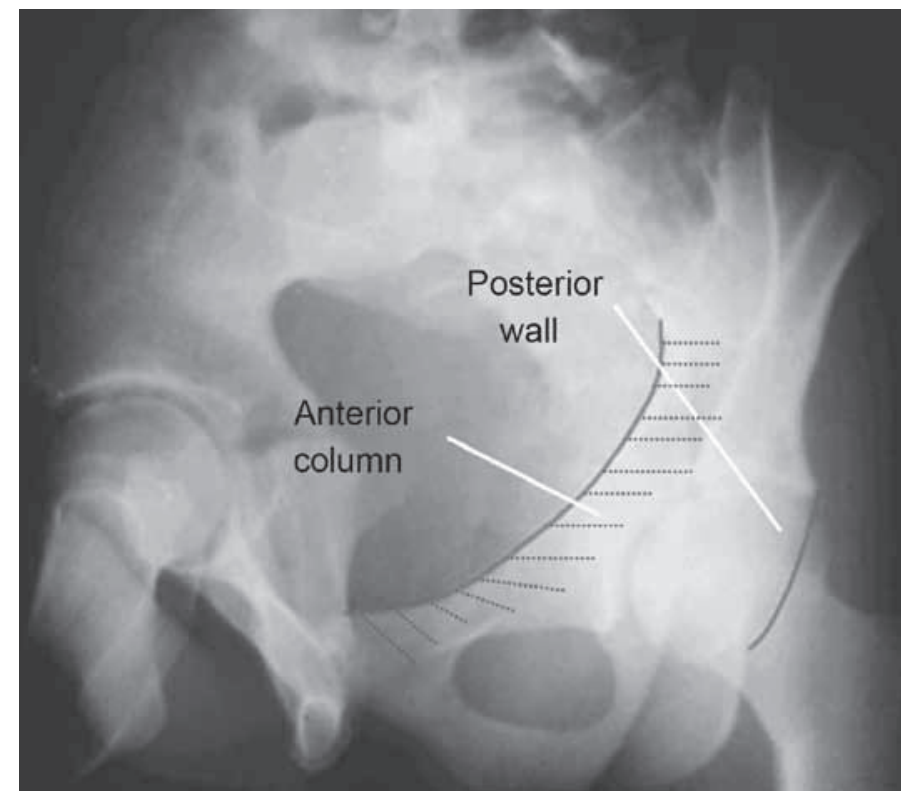

Figure 15 - Foraminal pelvic radiograph ofthe left hip.

3) Pelvic inlet ${ }^{(17)}$;

- Patient in horizontal supine position, with beam incident in the craniocaudal direction with angulation of $60^{\circ}$ (Figure 16);

- When properly executed, observe the promontory overlapping the anterior cortex of the $\mathrm{S} 1$ vertebral body ${ }^{(17)}$; - Indicated mainly for physical trauma (pelvic fracture); and

- It allows us to evaluate the integrity of the pelvic ring, as well as anteroposterior and rotational deviations.

4) Pelvic outlet ${ }^{(17)}$ :

- Patient in horizontal supine position, with beam incident in the caudocranial direction with angulation of $45^{\circ}$ (Figure 17);

- Technique properly executed when the upper part of the pubic symphysis is at the same level as the second sacral body;

- Indicated mainly for physical trauma (pelvic fracture); - It allows us to evaluate sacral fractures (to observe the wedge format when intact and to evaluate the outline of the foramens), as well as fractures of the posterior portion of the iliac wing and of the pubic ramus, sacroiliac disjunction and vertical deviations ${ }^{(17)}$.

\section{C) Suggestions of views by condition}

1) Coxarthrosis:

The AP pelvic radiograph is still the main examination, where it is possible to classify the degree of arthrosis. 

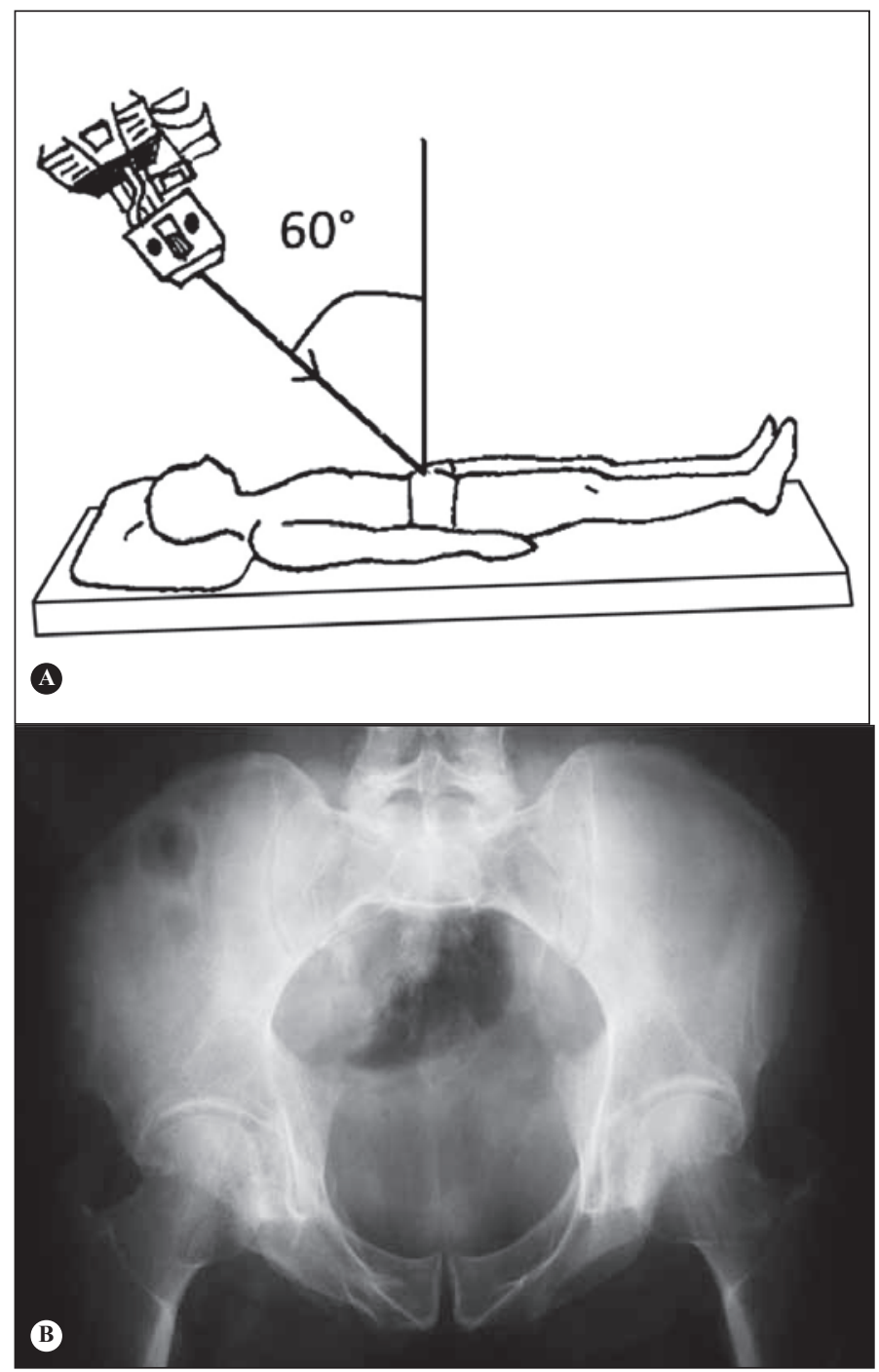

Figure 16 - Inlet view of pelvis. A) Patient in horizontal supine position, with beam incident in the craniocaudal direction with angulation of $60^{\circ}$. B) Inlet pelvic radiograph executed with correct technique. Observe the promontory overlapping the anterior cortex of the S1 vertebral body.

Another very useful view, particularly for initial cases of arthrosis, is Lequesne's false profile, as it evidences anterosuperior and medial impingement, often not clearly observed in the AP view (Figure 18), which can lead to inappropriate indications and surgeries.

2) Alterations in the acetabular morphology and depth:

The AP pelvic radiograph allows us to visualize alterations in the acetabular version, dysplasia, acetabular protrusion and coxa profunda.

Alterations in the acetabular depth should be based on the ilioischial line, and are called coxa profunda when the floor of the acetabulum touches the line and acetabular protrusion when the femoral head surpasses such line (Figure 19).

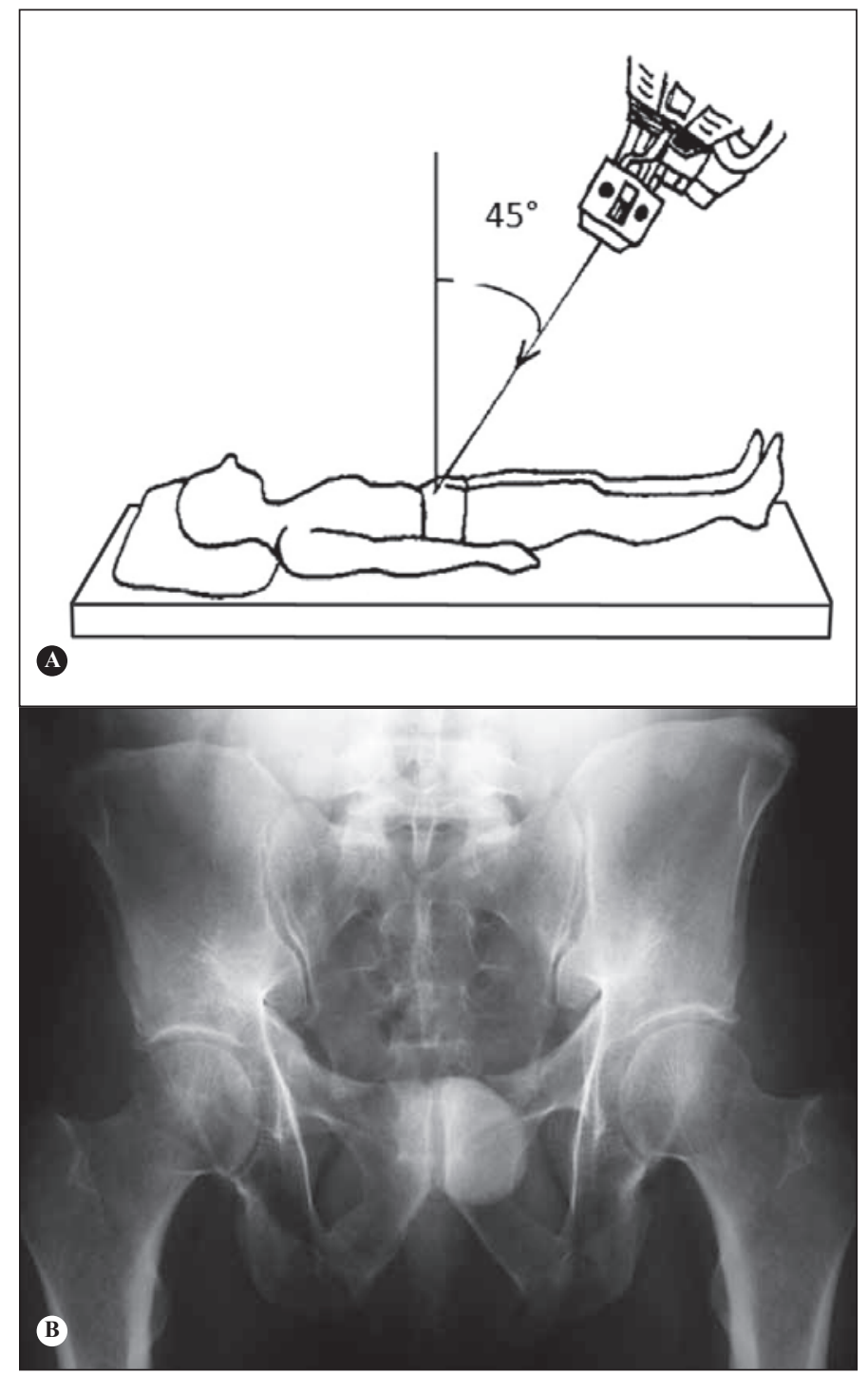

Figure 17 - Outlet view of the pelvis. A) Patient in horizontal supine position, with beam incident in the caudocranial direction with angulation of $45^{\circ}$. B) Outlet pelvic radiograph.

Lequesne's view is also useful in the evaluation of acetabular dysplasia, measuring the angle of anterior coverage of the femoral head, whose normal value is $25^{\circ}$ or higher $^{(2)}$ (Figure 20).

3) Femoroacetabular impingement:

With the AP radiograph we can evaluate the presence of deformity in the proximal portion of the femur, alterations in the acetabular version and dysplasia.

The Lequesne, Ducroquet and Dunn views are used to evaluate the sphericity of the cervicocephalic junction, mainly in the anterolateral portion, as well as the acetabular coverage of the femoral head. Through Lequesne's false profile view we can visualize potential excessive acetabular coverage (Pincer impingement $)^{(18)}$. 

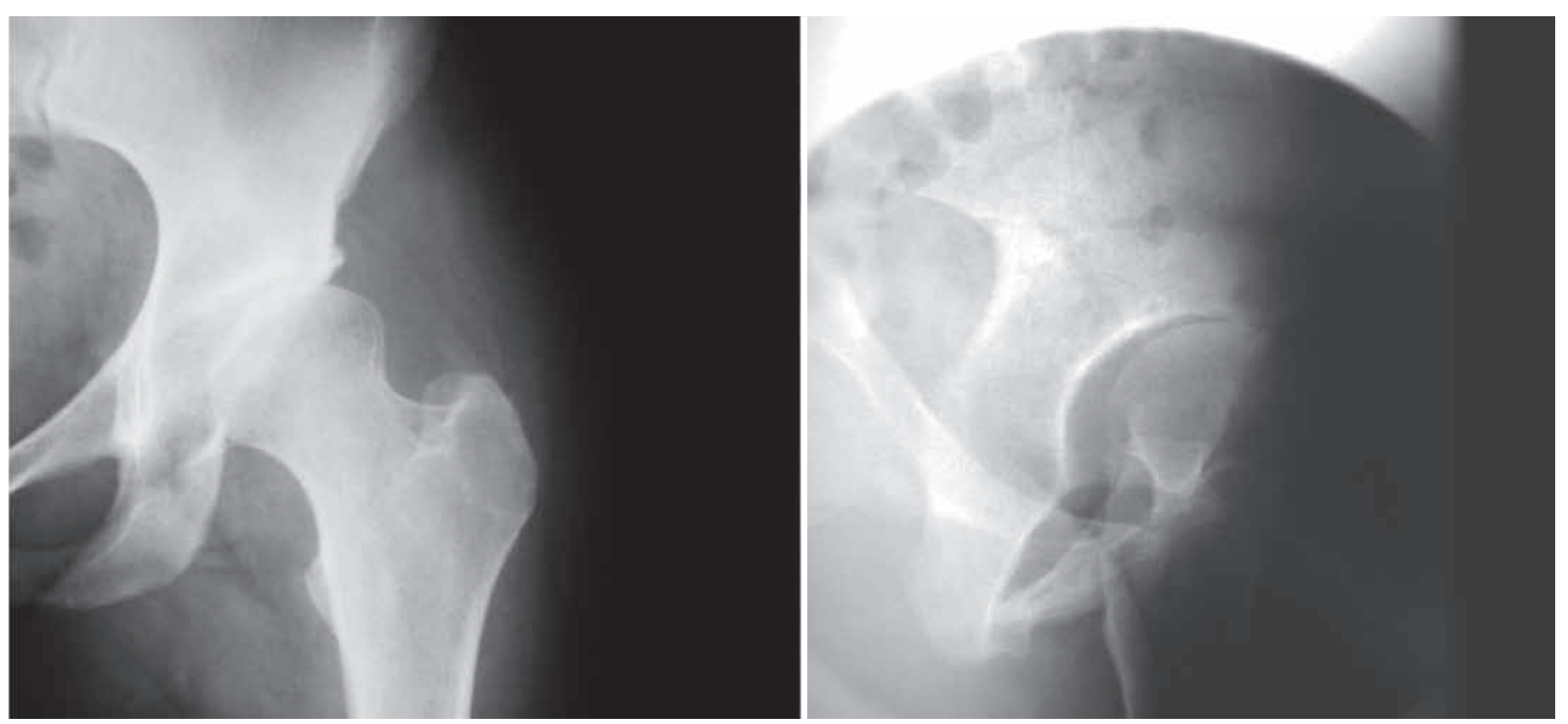

Figure 18 - AP view of left hip with slight anterosuperior impingement. Lequesne's false profileview of the same patient with more evident anterosuperior impingement.

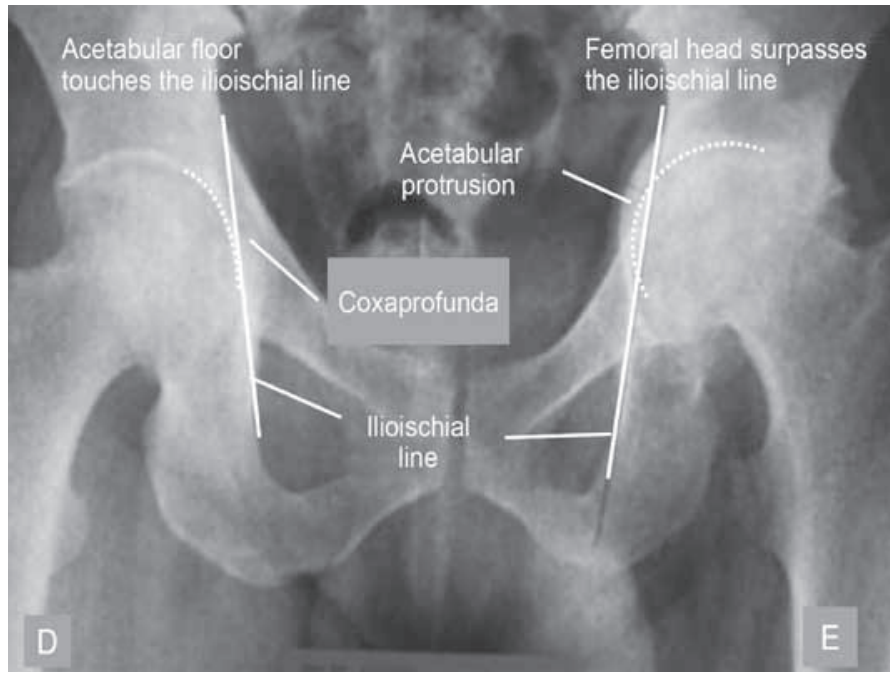

Figure 19 - AP pelvic radiograph with coxaprofunda of the right hip and protrusion of the left hip.

As described previously, the Dunn and Ducroquet views are useful to measure the alpha angle, important in the study of CAME impingement.

4) Fractures:

a) Pelvis - AP, inlet and outlet;

b) Acetabulum - AP, alar and foraminal; and

c) Fractures of the proximal third of the femur - AP, AP with traction and internal rotation (aiming to predict the degree of instability, and consequently, the surgical technical difficulty), cross table (an advantage in traumatized patients, since the affected hip is not mobilized).

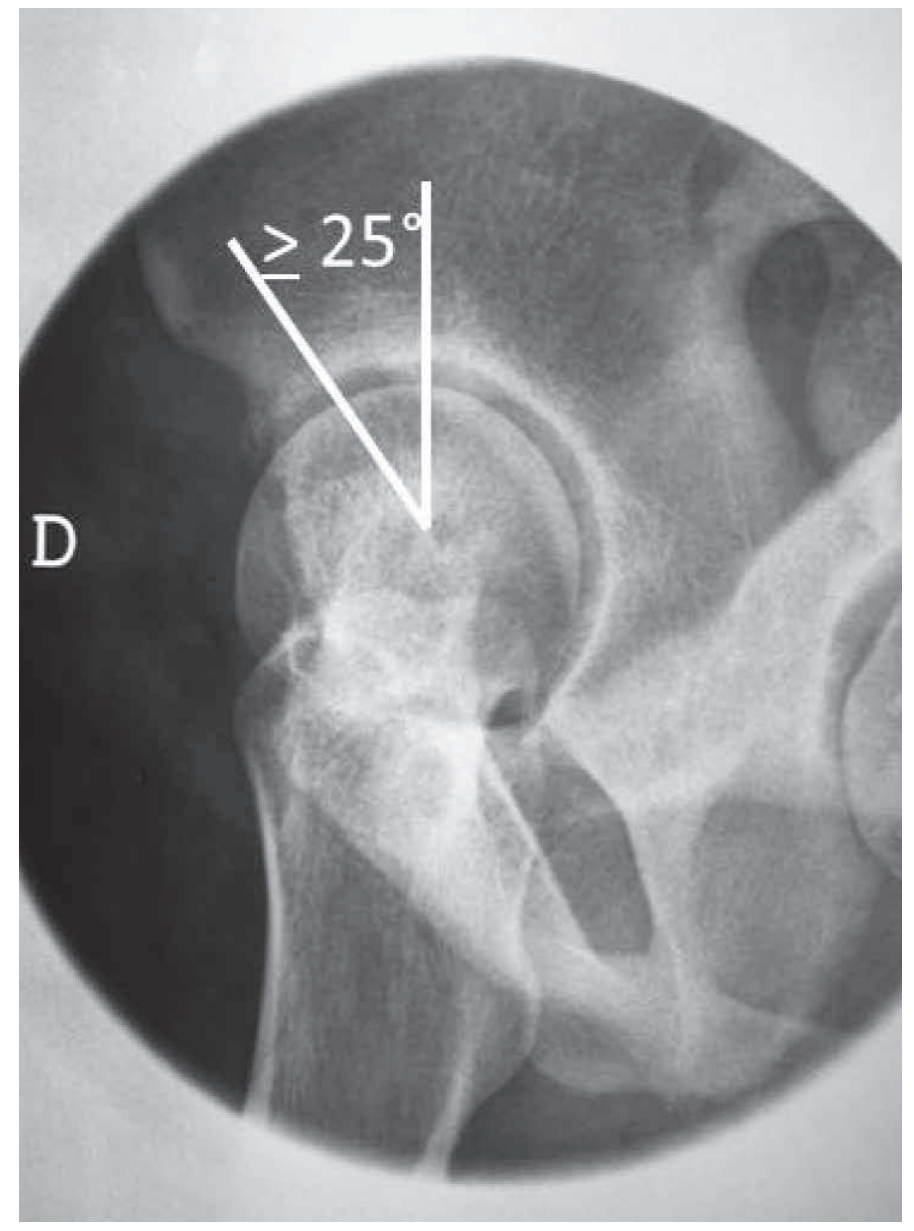

Figure 20 - Lequesne's false profile radiograph. Visibility of the angle of anterior coverage of the femoral head. The lines are drawn passing through the center of rotation of the femoral head, with one vertical and the other passing across the more ossified edge of the acetabular portion. 


\section{REFERENCES}

1. Clohisy JC, Carlisle JC, Trousdale R, Kim YJ, Beaule PE, Morgan P, StegerMay K, Schoenecker PL, Millis M. Radiographic evaluation of the hip has limited reliability. Clin Orthop Relat Res. 2009;467(3):666-75.

2. Godefroy D, Chevrot A, Morvan G, Rousselin B, Sarazin L. [Plain films of pelvis]. J Radiol. 2008;89(5 Pt 2):679-90.

3. Tannast M, Siebenrock KA, Anderson SE. Femoroacetabular impingement: radiographic diagnosis--what the radiologist should know. AJR Am J Roentgenol. 2007; 188(6):1540-52

4. Armbuster TG, Guerra J Jr, Resnick D, Goergen TG, Feingold ML, Niwayama G, Danzig LA. The adult hip: an anatomic study. Part I: the bony landmarks. Radiology. 1978;128(1):1-10.

5. Conrozier T, Lequesne MG, Tron AM, Mathieu P, Berdah L, Vignon E. The effects of position on the radiographic joint space in osteoarthritis of the hip. Osteoarthritis Cartilage. 1997;5(1):17-22.

6. Vanni GF, Stucky JM, Schwarstmann CR. Avaliação radiológica do espaço articular na artrose do quadril: estudo comparativo em decúbito e ortostatismo. Rev Bras Ortop. 2008;43(10):460-4

7. Auleley GR, Duche A, Drape JL, Dougados M, Ravaud P. Measurement of joint space width in hip osteoarthritis: influence of joint positioning and radiographic procedure. Rheumatology (Oxford). 2001;40(4):414-9

8. Vignon E, Conrozier T, Piperno M, Richard S, Carrillon Y, Fantino O. Radiographic assessment of hip and knee osteoarthritis. Recommendations: recommended guidelines. Osteoarthritis Cartilage. 1999;7(4):434-6.

9. Lequesne MG, Laredo JD. The faux profil (oblique view) of the hip in the standing position. Contribution to the evaluation of osteoarthritis of the adult hip. Ann Rheum Dis. 1998;57(11):676-81
10. Lequesne M, Laredo JD. The faux profil view of the hip may detect joint space narrowing when lacking on the anteroposterior radiograph in incipient osteoarthritis. Arthritis Rheum. 1998;41(Suppl):145.

11. Conrozier T, Bochu M, Gratacos J, Piperno M, Mathieu P, Vignon E. Evaluation of the 'Lequesne's false profile' of the hip in patients with hip osteoarthritis. Osteoarthritis Cartilage. 1999;7(3):295-300

12. Meyer DC, Beck M, Ellis T, Ganz R, Leunig M. Comparison of six radiographic projections to assess femoral head/neck asphericity. Clin Orthop Relat Res. 2006;445:181-5.

13. Polesello GC, Queiroz MC, Ono NK, Honda EK, Guimarães RP, Ricioli W. Tratamento artroscópico do impacto femoroacetabular. Rev Bras Ortop. 2009;44(3):230-38

14. Reilly MC. Fractures of the acetabulum. In: Bucholz RW, Heckman JD, CourtBrown CM, editors. Rockwood \& Green's fractures in adults. 6th ed. Philadelphia: Lippincott Williams \& Wilkins; 2006. p.1666- 714.

15. Judet R, Judet J, Letournel E. Fractures of the acetabulum: classification and surgical approaches for open reduction. Preliminary report. J Bone Joint Surg Am. 1964;46:1615-46.

16. Letournel E. Acetabulum fractures: classification and management. Clin Orthop Relat Res. 1980;(151):81-106.

17. Starr AJ, Malekzadeh AS. Fractures of the pelvic ring. Bucholz RW, Heckman JD, Court-Brown CM, editors. Rockwood \& Green's fractures in adults. 6th ed. Philadelphia: Lippincott Williams \& Wilkins; 2006. p. 1585-664

18. Crestani MV, Teloken MA, Gusmão PDF. Impacto femoroacetabular: uma das condições precursoras da osteoartrose do quadril. Rev Bras Ortop. 2006;41(8):285-93 